\title{
Assessing the Intensity of the Usability of the Course Content within the Virtual Learning Environment
}

\author{
https://doi.org/10.3991/ijet.v15i17.13715 \\ Juraj Obonya ${ }^{\bowtie}$, Miroslav Kadlečík \\ Constantine the Philosopher University in Nitra, Nitra, Slovakia \\ juraj.obonyadukf.sk
}

\begin{abstract}
Nowadays, education is a complex process that has many advantages. This is obviously proven, as there are high demands on skills in today's world. Therefore, it is a good approach to acquire this knowledge during the studies. Accordingly, there is a high requirement how to constantly improve and acquire new experiences. To meet as many of these parameters as possible, it is important that we have an appropriately structured environment for students. The teaching process can be interpreted in several ways. We focus on data analysis in the teaching process through e-learning systems. Obviously, these supporting systems have many advanced functionalities to make the entire learning process much easier to understand. In our work, we focus on methods and approaches by means of we can evaluate student behaviour and we can measure and evaluate the course settings. We used introductory programming courses for these measurement purposes. We explored various managerial settings inside a concrete course structure. Subsequently, we used statistical evaluation over the already cleaned and pre-processed data from the system. At the same time, based on these statistical confirmations, we can propose a set of methodological recommendations for the teacher, which will help us to improve the quality, feasibility of the entire teaching process.
\end{abstract}

Keywords - Activity evaluation, educational data mining, student behaviour, virtual learning environment.

\section{$1 \quad$ Introduction}

Nowadays e-learning is a constantly evolving area. We are dealing with an area which is extremely desirable, but not only in academic sphere but also in industry and other emerging sectors all around the world [1]. It is a form of education through which we can come to different kinds of information [50]. Nowadays, the e-learning is accessible from different devices, that makes this entire area more and more desirable [35]. The concept of lifelong learning is at the forefront and therefore the process of acquiring knowledge is very important [29]. The researchers described an appropriate usage of a support system is an essential approach how to facilitate and evaluate the accuracy of the entire learning process also by means of educational models [22] [28] [6]. The developed technology enhancements allow access to information from 
anywhere and anytime. Due to this access we can measure and track the behaviour of students [40]. E-learning has many advantages that make it easier for the teacher to work throughout the teaching process [13]. As a result, learning becomes a managed and controlled process that is accessible to everyone, since e-learning is a widely used part of the learning process [45]. For that purpose, it is mainly referred to the webbased environment, which is nearly related to the web applications and technologies [14]. Their aim is to provide a course or a specific content, or educational materials to students, to allow a remote form of education and to provide the choice to manage the entire learning process [12].

As stated in [14] [12] as well-set electronic learning environment implies several functionalities, that will help in teaching to achieve the set goals. The author's recommendations and reasons to implement and use e-learning systems in education are as follows: explore the circumstances that in some way lead to success or failure of users in e-learning and in online courses examine the suitability of elements that are present in e-learning.

Our investigated research problem is to find out which activities are important for the reliable measurement of the course activities. For that purpose, we compared introductory programming courses from different academic years. We will establish our findings and stands over reliable data from the learning environment and examined courses, which we want to evaluate. We will apply statistical methods over these extracted and pre-processed data. Our goal is to compare the same course with various modifications in two different academic years. Our expectation is to get an overview over these two courses and its activities. We also expect that we could form some managerial suggestions as improvements for the teacher, which will be stated from the statistical results.

\section{$2 \quad$ Related Work}

The usability concept for a system has been described from various points of view [20] [49]. Thanks to [42] [23] the LA (Learning Analytics) is a rapidly emerging field. LA represents a concrete field which deals with the optimization of the learning environment to improve the whole teaching process [37]. An important goal of educational institutions is to timely identify the deficiency in students' knowledge [5]. Universities and educational institutions are successfully involved in this growing initiative. The demonstrable result is the knowledge and conclusion of students are statistically evaluated [18].

\subsection{Learning analytics and course usability}

According to [10] the LA field LA can also be used in other sectors than in teaching, but LA's goal is to support the learning process by identifying the behaviour of teachers and students in a virtual learning environment [10]. For this purpose, there is a high demand to choose the appropriate algorithms and procedure to analyse the student's behaviour [25]. Similarly, if a successful student gives a low performance in 
the assignment or role or asks repeatedly for materials or procedures. The teacher can also determine how often has the concrete student accessed to these materials. This approach with the course usability was described by other researchers [52]. By means of the LA we can evaluate the quality and beneficial asset of different course components and sections [9] [46].

\subsection{Course outcomes and course assessing}

To assess the effectiveness of the learning process, it is important to mention the specific learning outcomes of courses, which are also referred to as course outcomes in the literature [51]. The outcomes of the courses can be defined as a form of a specific description of the student's knowledge acquired by the student after carrying out a certain course activity. Each output is scored according to the selected scale. Outcomes in Moodle help the teacher monitor progress with students. This approach allows us to analyse the student's activities [38] and state some recommendations for further purposes [44]. According to [19] course outcomes are a formal outcome of what students should achieve in a concrete given course. The outputs are a detailed knowledge, practical skills, creativity. In teaching and translating the whole course, the teacher expects, that students gradually acquire these expected outcomes [48].

\section{Methodology}

In our research we are dealing with a concrete introductory programming course. Introductory programming course represent the most important milestone in the education of students in computer science. Many students can get a job as a programmer [11]. Due to other methodologies a programming course is a very appropriate form, how to identify the suitability of the given course [47] [31]. We defined hypotheses in our research, which should be proven, over a statistical evaluation and interpretation of extracted data [3]. The course is divided into chapters, which are predetermined to explain the programming studies of students. These chapters include study materials, animations, graphic representations testing or other various activities [7]. Our methodology is based over statements of researchers, to reveal the rate of the course usage by students [41].

\subsection{Introductory programming course as a source subject to the research}

The aim of this introductory programming course is to inform students with the basic principles of programming. The prerequisite for the completion of the course is that students must acquire the basic knowledge and skills how to create a program and how to develop their own algorithmic thinking [32], by means of an appropriated engagement [34]. They must become more familiar with the principles of the objectoriented programming. We used an implemented introductory programming course [17] on portal: https://edu.ukf.sk/ 
The introductory programming course was divided into various sections and chapters [33], that follow each other and based on which students acquire basic programming and algorithmic thinking skills.

In our research we used the following methodologies:

- We defined the programming course and all its activities in separated years as subject for our research

- We stated H0 hypotheses for the examined variables in the courses

- We used exploratory analysis for the researched activities in the courses

To verify the stated hypothesis, we will proceed as follows:

- Data acquisition and preparation - pre-processing from the log file from Moodle, division of the retrieved data, creation of the groups etc.

- Data Analysis - the input data file contains data about the activities of 182 students in the course of Programming for two semesters. All activities from the introductory programming course at https://edu.ukf.sk.

- Descriptive approach - we provided descriptive statistics for each course activities about the students.

- Analytical approach - we can prove or reject the stated hypotheses by means of the evaluated data.

\subsection{Programming course as a source subject to the research}

The number and type of each individual activity, which are available for students in the Programming course is a prerequisite for the most accurate analysis and statistical evaluation. We classified students be means of the selected activities in the course. The Table 1 gives an overview of the frequency of each Moodle activity in the course.

Table 1. Count of individual activities in the course Programming different years

\begin{tabular}{|l|c|c|c|}
\hline \multicolumn{1}{|c|}{ Type of the activity } & $\mathbf{2 0 1 6}$ & $\mathbf{2 0 1 7}$ & $\mathbf{2 0 1 8}$ \\
\hline Assign & 20 & 20 & 15 \\
\hline Book & 9 & 9 & 9 \\
\hline Feedback & 4 & 5 & 2 \\
\hline Forum & 6 & 5 & 4 \\
\hline Label & 27 & 32 & 39 \\
\hline Page & 22 & 23 & 21 \\
\hline Quiz & 16 & 24 & 15 \\
\hline Resource & 68 & 60 & 64 \\
\hline URL & 28 & 37 & 48 \\
\hline VPL & 1 & 31 & 230 \\
\hline Sum & 201 & 246 & 447 \\
\hline
\end{tabular}

The entire teaching process is complex, and it continuously undergoes through various additional improvements. From the Table 1 is obvious, that the programming course is constantly being developed and modified. 


\subsection{Enrolled students in the programming course}

Every year more and more students attend to the subject of programming (see Table 2). Students of applied informatics must pass through this subject obligatory. The main advantage of this course is to acquire the basic principles of programming and the algorithmic thinking knowledge of programming. This knowledge will help them solve other problems more effectively from other areas, such as. data analysis, computer networks, etc.

Table 2. Count of the enrolled students in the course in separated academic years

\begin{tabular}{|c|c|}
\hline Year & The count of enrolled students in the course \\
\hline 2018 & 108 \\
\hline 2017 & 82 \\
\hline 2016 & 64 \\
\hline
\end{tabular}

The student classifications are feasible, because it's based on the extracted data from the education system. According to [1] data extraction refers to the process by means of we can get relevant properties and behaviour of students [4]. We can obtain information to determine the behaviour of students in the learning environment, which will ultimately help us to identify the learning style. With these findings, we can provide the teacher with an overview of the students and the entire educational process. In the research [27] the author gives an opinion which learning styles are integrated in the electronically supported education. The basis of this research is demonstrably the level of available data. As more useful data is available to us, we can more accurately integrate these aspects of e-learning.

Through obtaining and cleaning this data, we can identify important information such as:

- The number of all students enrolled in the course

- Number of students' enrolments

- The number of clicks on each course material.

Based on this information, we can classify students who use the course working in it. By means of our described methodology and results interpretation we can improve the learning process. The types of the possible improvements are:

- Monitoring the performance of individual students

- Distribution of students according to their performance

- Identification of outliers, data for the early intervention of teacher

- Predicting the student's potential for all students to achieve optimal results

- Avoid the dropping in the course attendance

- Development of instructional techniques (e.g. course management)

- Analysis and evaluation of standard tools and methods

- Curriculum assessment 


\section{Results}

Our main goal of the research was to create an overview supporting suggestions for teachers that will evaluate the intensity of the usability of course content. Based on the methodology we analysed the recorded student activity and the success of activities in the virtual learning environment [24]. In our results explorations we focused on the hypothesis's formulation in consideration of the defined research problem. The accuracy and quality of our research results depends on the number of analysed activities (Monsen, 2006), where decision trees were used as a method to identify important activities.

We investigated the data distribution and we assumed the certain relationships between variables. We compared mean and dispersion rates and examine timedependent data.

\subsection{Activities and student's evaluation in the course}

From the teacher's point of view, we need to identify a student's transition through a specific course in a VLE environment [15]. We need to statistically verify whether the student's transition through the course meets our criteria.

The first phase of the experiment was to verify the comparability of students (over the years under review). The comparability of the groups was determined by a pre-test performed at the beginning of the semester. The knowledge of the students before the beginning of the programming course depended on the previous knowledge which was gained at the secondary school. Data was collected through an input questionnaire.

The questionnaire contained 39 items. The items were focused on areas such as: how the lessons were held in computer science, how many times a week student had a computer lesson, etc. This "result of self-assessment" of students was a pre-test variable that expresses the self-assessment of the knowledge level from computer science. From the obtained results we identified and compared the knowledge of students in individual years.

Primarily, the logging records from the Programming course were chosen for the realization of the experiment. The activities of the students were monitored during two semesters: winter semester 2017 and winter semester 2018. An important factor in the choice of the Programming for our experiment was, that the course went between these two semesters in years: 2017 and 2018 with a fundamental structure change as well as minor adjustments to the course content. Activities and teaching materials were rearranged in the course. 


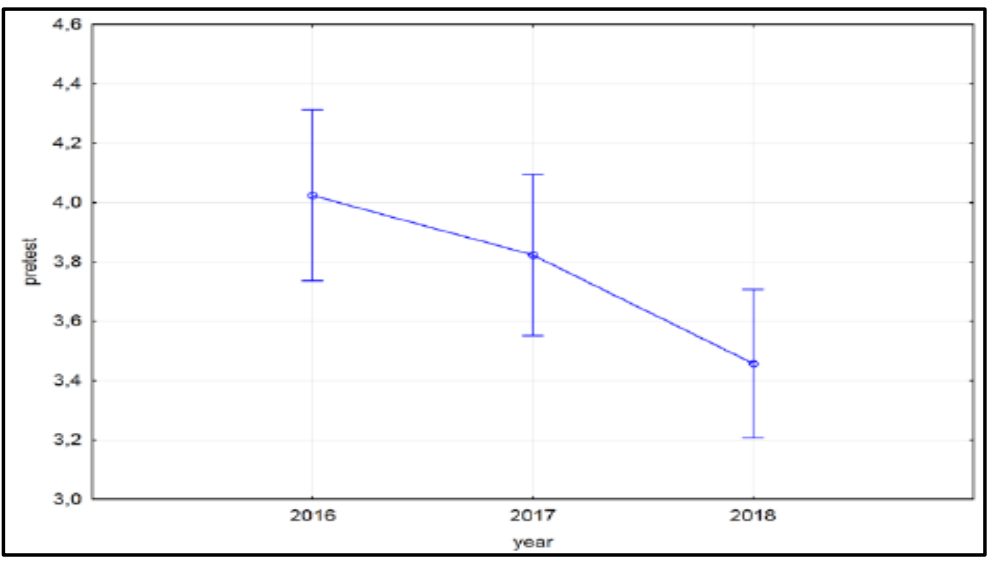

Fig. 1. Comparison of the pre-test scores in the surveyed years

After the comparison of the groups of students with statistically comparable results we obtained the data from the years 2017 and 2018.

\subsection{Hypotheses formulation}

Based on the result of analysis of variance, we reject the null hypothesis at the $5 \%$ significance level, which claims that results of the test do not depend on the year. We need to verify the validity of the following hypotheses:

- H0: There is no statistically significant difference in knowledge in the field between the control (2017) and the experimental (2018) groups

- H0: Activity in the course, in the "forum" section, does not depend on the course structure

- H0: Activity in the course, in the "file" section, does not depend on the course structure

- H0: Activity in the course, in the "page" section, does not depend on the course structure

- H0: Activity in the course, in the "URL" section, does not depend on the course structure

- H0: The variables which are describing the "file", "page", "URL" activities are independent in consideration of the course structure

The first hypothesis was verified above and confirmed the equivalence of both groups. Our goal is to reject the third, fourth and fifth hypotheses. By rejecting these hypotheses, alternative hypotheses come into force, claiming that activity in the course depends on changes in the course structure in section, forum, file, page, and URL.

The alternative hypothesis can be formulated as follows: 
- H1: Provided activities by students in the programming course depends on the course structure, which is made by "file", "page" and "URL" sections

In establishing these hypotheses, we described the variables, that we will analyze in our research.

\subsection{Exploration of the evaluated records from course}

By visualizing the distribution, we check the normality of all dependent variables: forum, page, file, URL. Based on the independent variable factor level in 2017 and 2018. We will verify this assumption by checking the categorized normal probability plot (see Table 3).

Table 3. Descriptive statistics for the investigated course activities

\begin{tabular}{|c|c|c|c|}
\hline & Completely & Year & Year \\
\hline Level & & 2017 & 2018 \\
\hline $\mathrm{N}$ & 163 & 85 & 78 \\
\hline Forum mean & 5.56 & 4.99 & 6.19 \\
\hline Forum standard deviation & 6.02 & 5.52 & 6.51 \\
\hline Forum error & 0.47 & 0.60 & 0.74 \\
\hline Forum $-95.00 \%$ & 4.63 & 3.80 & 4.72 \\
\hline Forum $+95.00 \%$ & 6.50 & 6.18 & 7.66 \\
\hline Book mean & 9.99 & 11.54 & 8.31 \\
\hline Book standard deviation & 12.18 & 14.04 & 9.56 \\
\hline Book error & 0.95 & 1.52 & 1.08 \\
\hline Book $-95.00 \%$ & 8.11 & 8.51 & 6.15 \\
\hline Book $+95.00 \%$ & 11.88 & 14.57 & 10.46 \\
\hline Page mean & 6.60 & 6.44 & 6.77 \\
\hline Page standard deviation & 5.91 & 5.90 & 5.96 \\
\hline Page error & 0.46 & 0.64 & 0.67 \\
\hline Page $-95.00 \%$ & 5.68 & 5.16 & 5.43 \\
\hline Page $+95.00 \%$ & 7.51 & 7.71 & 8.11 \\
\hline File mean & 8.33 & 7.82 & 8.87 \\
\hline File standard deviation & 6.09 & 5.97 & 6.21 \\
\hline File error & 0.48 & 0.65 & 0.70 \\
\hline File $-95.00 \%$ & 7.38 & 6.53 & 7.47 \\
\hline File $+95.00 \%$ & 9.27 & 9.11 & 10.27 \\
\hline Test mean & 117.25 & 123.00 & 110.97 \\
\hline Test standard deviation & 54.67 & 52.84 & 56.27 \\
\hline Test error & 4.28 & 5.73 & 6.37 \\
\hline Test $-95.00 \%$ & 108.79 & 111.60 & 98.29 \\
\hline Test $+95.00 \%$ & 125.70 & 134.40 & 123.66 \\
\hline URL mean & 10.31 & 7.02 & 13.88 \\
\hline URL standard deviation & 10.26 & 9.56 & 9.85 \\
\hline URL error & 0.80 & 1.04 & 1.12 \\
\hline URL $-95.00 \%$ & 8.72 & 4.96 & 11.66 \\
\hline URL +95.00\% & 11.89 & 9.08 & 16.11 \\
\hline
\end{tabular}


The table 3 contains descriptive statistics (mean, standard deviation, standard error, and $95 \%$ confidence interval for the mean) for the control and the experimental groups either in the years $2017-2018$.

Table 4. Results of the analysis of variance for pretest

\begin{tabular}{|l|c|c|c|c|c|}
\hline & df & pretest SS & pretest MS & pretest F & pretest p \\
\hline Intercept & 1 & 2704.599 & 2704.599 & 2270.227 & $0.0000^{* * *}$ \\
\hline Year & 2 & 10.860 & 5.430 & 4.558 & $0.0117^{*}$ \\
\hline Error & 190 & 226.353 & 1.191 & & \\
\hline Total & 192 & 237.213 & & & \\
\hline
\end{tabular}

Note: $*=\mathrm{p}<0.05 ; * * *=\mathrm{p}<0.001$

After the rejection of null hypothesis, we are interested in which years were statistically significant differences. Subsequently after a multiple comparison, we identified statistically significant differences between years 2016 and 2018.

Table 5. Multiple comparisons: Tukey test

\begin{tabular}{|l|c|c|c|c|}
\hline & year & $\{\mathbf{1}\} \mathbf{4 . 0 2 3 8}$ & $\{\mathbf{2}\} \mathbf{3 . 8 2 2 8}$ & $\{\mathbf{3}\} \mathbf{3 . 4 5 7 2}$ \\
\hline$\{1\} 4.0238$ & 2016 & & 0.5929 & $0.0166^{*}$ \\
\hline$\{2\} 3.8228$ & 2017 & 0.5929 & & 0.1446 \\
\hline$\{3\} 3.4572$ & 2018 & $0.0166^{*}$ & 0.1446 & \\
\hline
\end{tabular}

Note: $*=\mathrm{p}<0.05$

As a result of comparing students as shown in Table 5, the student groups in 2017 and 2018 are comparable. Comparability of student groups is also shown because of the Tukey test results.

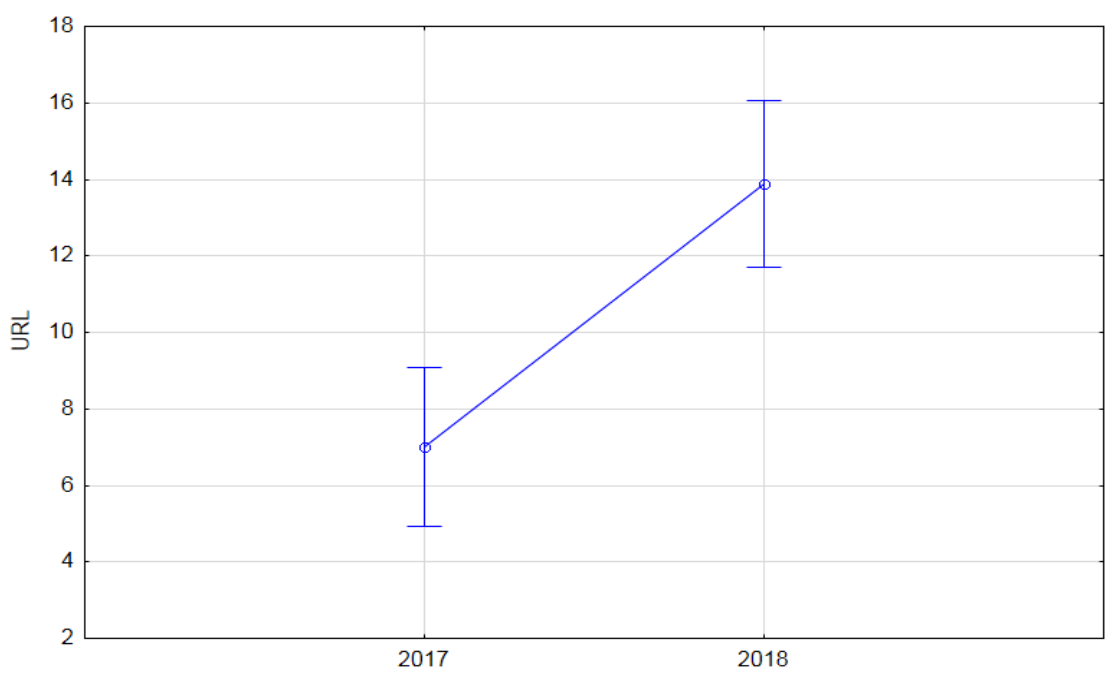

Fig. 2. Statistically significant differences in URL activities in given years 
In the pre-experiment results we chose comparable groups, equivalent in the pretest, whose knowledge levels were comparable, i.e. groups from 2017 and 2018. We compared exchange rate activities, that were the same and comparable in both years.

From the input data table, we obtained the following information, from which we created descriptive statistics. Through this approach we got the mean, standard deviation, standard error, and $95 \%$ confidence interval for the mean) for the control and the experimental groups either in the years 2017 - 2018.

The above described table contains descriptive statistics (mean, standard deviation, standard error, and 95\% confidence interval for the mean) for the control and the experimental groups either in the years $2017-2018$.

Table 6. Test of equality of variance

\begin{tabular}{|l|c|c|c|c|c|}
\hline & Hartley F-max & Cochran C & Chi-square & df & p \\
\hline Forum & 1.3926 & 0.5820 & 2.1899 & 1 & 0.1389 \\
\hline Page & 1.0197 & 0.5049 & 0.0076 & 1 & 0.9307 \\
\hline File & 1.0794 & 0.5191 & 0.1166 & 1 & 0.7327 \\
\hline URL & 1.0628 & 0.5152 & 0.0740 & 1 & 0.7856 \\
\hline
\end{tabular}

Tests are statistically insignificant $(\mathrm{p}>0.05)$, the equality of dispersion hypothesis was not rejected. It can be stated that the assumption was not violated, which was also confirmed by the non-parametric Levene's test, given the identified deviations from normality.

Table 7. Nonparametric Levene's test of homogenity

\begin{tabular}{|l|c|c|c|c|}
\hline & MS Effect & MS Error & F & p \\
\hline Forum & 69.4590 & 18.1643 & 3.8239 & 0.0523 \\
\hline Page & 0.4393 & 14.7505 & 0.0298 & 0.8632 \\
\hline File & 1.6354 & 14.0312 & 0.1166 & 0.7332 \\
\hline URL & 10.6959 & 43.6152 & 0.2452 & 0.6211 \\
\hline
\end{tabular}

After the verification of the introductory assumptions, the results of the variance analysis can be considered valid as follows. Significant value of F statistics leads to the rejection of the null hypothesis, so we reject $\mathrm{HO}$ only in case of URL, in the remaining three cases there were no statistically significant differences. The changes in the structure have no effect in activities like forum, page and file. In the URL section, we can confirm that the structure change had a statistically significant effect in this course. 
Table 8. Analysis of variance for individual course activities

\begin{tabular}{|l|c|c|c|c|}
\hline & Intercept & Year & Error & Total \\
\hline df & 1 & 1 & 161 & 162 \\
\hline Forum MS & 5084.5410 & 58.9700 & 5821.1040 & 5880.0740 \\
\hline Forum MS & 5084.5410 & 58.9700 & 36.1560 & \\
\hline Forum F & 140.6281 & 1.6310 & & \\
\hline Forum p & $0.0000^{* * *}$ & 0.2034 & & \\
\hline Page MS & 7092.0450 & 4.5360 & 5658.7400 & 5663.2760 \\
\hline Page MS & 7092.0450 & 4.5360 & 35.1470 & \\
\hline Page F & 201.7798 & 0.1291 & & \\
\hline Page p & $0.0000^{* * *}$ & 0.7199 & & \\
\hline File MS & 11337.4600 & 44.7000 & 5965.0700 & 6009.7700 \\
\hline File MS & 11337.4600 & 44.7000 & 37.0500 & \\
\hline File F & 306.0032 & 1.2064 & & \\
\hline File p & $0.0000^{* * *}$ & 0.2737 & & \\
\hline URL MS & 17781.0300 & 1914.7500 & 15145.9100 & 17060.6600 \\
\hline URL MS & 17781.0300 & 1914.7500 & 94.0700 & \\
\hline URL F & 189.0111 & 20.3536 & & \\
\hline URL p & $0.0000^{* * *}$ & $0.0000^{* * *}$ & & \\
\hline
\end{tabular}

Note: $* * *=p<0.001$

\section{Discussion}

This study reveals the statistical analysis, that describes a complex view of the data to confirm or reject the stated hypotheses. We proved a set of suggestions in the teaching process of introductory programming courses [47] [21] [39].

We analysed significant activities through statistical evaluation [43]. The beneficial aspect is, that all these findings and reports can be easily interpreted and visualized [30]. We confirmed the key activities in the course, and we compared them in pursuance of the student's activities and their knowledge in the specific virtual environment in higher education [26]. We compared the two groups of students if they are comparable. We tested the null hypotheses of collected and prepared data. It was set on statistical analysis [2]. We were relying on data analysis in the Moodle environment [16] [8].

Based on these exploratory analyses we can conclude that the managerial changes [36] in the course basically increased the visit rate on the selected activities, which helped the students to receive better evaluation results from the subject.

\section{Conclusion and Future Work}

The main aim of our research was to find out which activities of the training course are important for the final evaluation of students from the subject Programming and Data Structures. We added an approach to our solution for the course evaluation. Through this approach we identified whether the level of effort of students to attend 
individual activities corresponds to the ac-quired knowledge and whether the resulting evaluation is reflected in these facts.

We clearly demonstrated statistically [8] significant differences in URL activities, which represented video tutorials about the basics of programming. This is very important because URL activities were references to introductory video tutorials. It is therefore clear that in 2018 students attended video tutorials more often. We found that the change in the course structure led to an increased interest of students in their studies. However, this is only demonstrable for URL activities. Conversely, a significant decrease was demonstrated in testing activities. The reason for the decline in testing activities was the transfer of students to VPL programming activities, where they were able to practice programming skills. The results of algorithms were automatically evaluated. The second reason was that test-type activities were voluntary for students during semester 2018 (i.e. they were understood as self-tests) and on the contrary they were mandatory in 2017.

In other activities statistically significant differences were not confirmed. This is also explained by the lower level of students' knowledge in 2018. Despite the findings of the test of comparability of groups, where statistically significant differences in the knowledge level of the groups studied were not confirmed, from descriptive statistics. We proved that the student's activities are emerged when we changed the course management. We can prove that the course management affects student activity in the given virtual learning environment, what is based on our previous findings. We proved our hypothesis in our research, which confirmed the importance of the establishment for a concrete analytical support for the teacher to make beneficial decisions.

This study like other researches already has limitations. A possible limitation is that the analysis was provided over introductory programming courses in various academic years from a single department with mainly the same curriculum.

\section{$7 \quad$ Acknowledgement}

The research leading to these results has received funding from the Erasmus+ project FITPED - Work-Based Learning in Future IT Professionals Education (Erasmus+ programme grant no. 2018-1-SK01-KA203-046382) and project Innovative Methods in Programming Education in the University Education of Teachers and IT Professionals (KEGA 029UKF-4/2018).

\section{$8 \quad$ References}

[1] Abdullah, M., Alqahtani, A., Aljabri, J., Altowirgi, R., \& Fallatah, R. (2015). Learning Style Classification Based on Student's Behavior in Moodle Learning Management System. Transactions on Machine Learning and Artificial Intelligence, 3(1). https://doi.org/10.14738/tmlai.31.868

[2] Adeniji, K. (2017). Educational Research and Hypotheses Testing: Reason or Ritual Educational Research and Hypotheses Testing: Reason or Ritual By Federal University Dutsinma, Department of Science Education, Katsina State, Nigeria. March. 
[3] Benjamin, D. J., \& Berger, J. O. (2019). Three Recommendations for Improving the Use of p-Values. American Statistician, 73(sup1), 186-191. https://doi.org/10.1080/00031305.20 $\underline{18.1543135}$

[4] Bentley, Y., Selassie, H., \& Shegunshi, A. (2012). Design and Evaluation of StudentFocused eLearning. Electronic Journal of E-Learning, 10(1), 1-12.

[5] Beth, Dietz-Uhler, J. E. H. (2013). Using Learning Analytics to Predict (and Improve) Student Success: A Faculty Perspective. Journal of Interactive Online Learnin, 12(1), 1726. https://doi.org/10.1109/ICALT.2013.126

[6] Blandin, B. (2011). Usability Evaluation of Online Learning Programs. Usability Evaluation of Online Learning Programs, June 2003. https://doi.org/10.4018/9781591401056.ch0 $\underline{17}$

[7] Bogaerts, S. A. (2017). One step at a time: Parallelism in an introductory programming course. Journal of Parallel and Distributed Computing, 105, 4-17. https://doi.org/10.1016/ j.jpdc.2016.12.024

[8] Bovo, A., Sanchez, S., Heiguy, O., \& Duthen, Y. (2013). Analysis of students clustering results based on Moodle log data. Proceedings of the 6th International Conference on Educational Data Mining, 306-307. http://www.educationaldatamining.org/EDM2013/papers/ rn_paper_54.pdf

[9] Demazière, C., \& Stöhr, C. (2015). Using Learning Analytics in Virtual Learning Environments. November.

[10] Dziuban, C., Patsy, M., Cavanagh, T., \& Watts, A. (2012). Analytics that Inform the University: Using Data you Already have. Journal of Asynchronous Learning Networks, 16(3), 21-38. https://doi.org/10.24059/olj.v16i3.276

[11] Elmaleh, J., \& Shankararaman, V. (2017). Improving student learning in an introductory programming course using flipped classroom and competency framework. IEEE Global Engineering Education Conference, EDUCON, 49-55. https://doi.org/10.1109/EDUCON. 2017.7942823

[12] Freire, L. L., Arezes, P. M., \& Campos, J. C. (2012). A literature review about usability evaluation methods for e-learning platforms. Work, 41(SUPPL.1), 1038-1044. https://doi. org/10.3233/WOR-2012-0281-1038

[13] Hazzan, O., Lapidot, T., \& Noa, R. (2014). Guide to teaching Computer Science: An Activity-Based Approach (2st. Editi). Springer London.

[14] Holsapple, C. W., \& Lee-Post, A. (2006). Defining, Assessing, and Promoting E-Learning Success: An Information Systems Perspective*. Decision Sciences Journal of Innovative Education, 4(1), 67-85. https://doi.org/10.1111/j.1540-4609.2006.00102.x

[15] Hussain, S., Muhsin, Z. F., Salal, Y. K., Theodorou, P., Kurtoğlu, F., \& Hazarika, G. C. (2019). Prediction model on student performance based on internal assessment using deep learning. International Journal of Emerging Technologies in Learning, 14(8), 4-22. https:// doi.org/10.3991/ijet.v14i08.10001

[16] Iglesias-Pradas, S., Ruiz-De-Azcárate, C., \& Agudo-Peregrina, Á. F. (2015). Assessing the suitability of student interactions from Moodle data logs as predictors of cross-curricular competencies. Computers in Human Behavior, 47, 81-89. https://doi.org/10.1016/j.chb.20 $\underline{14.09 .065}$

[17] Kalogiannakis, M., \& Papadakis, S. J. (2019). Evaluating a course for teaching introductory programming with Scratch to pre-service kindergarten teachers International Journal of Technology Enhanced Learning, 11(3), 231-246. https://doi.org/10.1504/IJTEL.2019.1002 $\underline{0447}$

[18] Keller, C., Hrastinski, S., \& Carlsson, S. a. (2007). Students' acceptance of e-learning environments: a comparative study in Sweden and Lithuania. European Conference on In- 
formation Systems (ECIS), 2007, 395-406. https://doi.org/10.1093/oxfordhb/97801992388 28.013.0022

[19] Kennedy, D., Bolgna, P., \& Edwards, I.-S. A. (2007). A Practical Guide Writing and Using Learning Outcomes A Practical Guide Writing and Using Learning Outcomes Writing and Using Learning Outcomes A Practical Guide (p. 53). https://doi.org/10.4324/97802034171 95_chapter_5

[20] Madan, A., \& Dubey, S. K. (2012). Usability Evaluation Methods: a Literature Review. International Journal of Engineering Science and Technology, 4(02), 590-599.

[21] Mason, R., Cooper, G., \& Raadt, M. De. (2012). Trends in Introductory Programming Courses in Australian Universities - Languages, Environments and Pedagogy. 14th Australasian Computing Education Conference, June 2014, 33-42. https://doi.org/10.1111/j.16 00-0765.2010.01324.x

[22] Mbati, L., \& Minnaar, A. (2015). Guidelines towards the facilitation of interactive online learning programmes in higher education. International Review of Research in Open and Distance Learning, 16(2), 272-287. https://doi.org/10.19173/irrodl.v16i2.2019

[23] Mishra, A., Bansal, R., \& Singh, S. N. (2017). Educational data mining and learning analysis. 2017 7th International Conference on Cloud Computing, Data Science \& Engineering Confluence, 491-494. https://doi.org/10.1109/CONFLUENCE.2017.7943201

[24] Młynarska, E., Greene, D., \& Cunningham, P. (2016). Indicators of Good Student Performance in Moodle Activity Data. February 2017. http://arxiv.org/abs/1601.02975

[25] Mohamad, S. K., \& Tasir, Z. (2013). Educational Data Mining: A Review. Procedia - Social and Behavioral Sciences, 97, 320-324. https://doi.org/10.1016/j.sbspro.2013.10.240

[26] Monsakul, J., \& Ed, D. (2007). Learning Management Systems in Higher Education: A Review from Faculty Perspective. 1-7.

[27] Monsen, R. (2006). In-Depth Analysis of the Felder-Silverman Learning Style Dimensions. Journal of Pediatric Nursing, 21(3), 242-243 2p. http://search.ebscohost.com/loginaspx?direct=true \&db=rzh\&AN=106333071\&site=ehost$\underline{\text { live }}$

[28] Moule, P. (2007). Challenging the five-stage model for e-learning: a new approach. Alt-J, 15(1), 37-50. https://doi.org/10.1080/09687760601129588

[29] Mouzakitis, G., \& Tuncay, N. (2018). E-Learning and lifelong learning E-LEARNING AND LIFELONG LEARNING. December.

[30] Nagi, K. (2015). Research Analaysis of Moodle Reports to Gauge the Level of Interactivity in Elearning Courses at Assumption University, Thailand. June 2008. https://doi.org/10. 1109/ICCCE. 2008.4580710

[31] Ocheja, P., Oyelere, S. S., \& Balogun, O. S. (n.d.). Analyzing Student Performance in Programming Education Using Classification Techniques. 15(2), 127-144.

[32] Orfanakis, V., \& St, P. (n.d.). Teaching basic programming concepts to novice programmers in Secondary Education using Twitter, Python, Ardruino and a coffee machine.

[33] Papadakis, S. J., Kalogiannakis, M., Orfanakis, V., \& Zaranis, N. (2017). The appropriateness of Scratch and App Inventor as educational environments for teaching introductory programming in Primary and Secondary education. International Journal of Web-Based Learning and Teaching Technologies (IJWLTT), 12(4), 58-77. https://doi.org/10.4018/IJ WLTT.2017100106

[34] Papadakis, S., \& Kalogiannakis, M. (2017). Using Gamification for Supporting an Introductory Programming Course. The Case of ClassCraft in a Secondary Education Classroom. In Interactivity, Game Creation, Design, Learning, and Innovation (pp. 366-375). Springer, Cham. https://doi.org/10.1007/978-3-319-76908-0_35 
[35] Papadakis, S., Kalogiannakis, M., \& Sifaki, E. (2018). Access Moodle Using Smart Mobile Phones . A Case Study in a Greek University In Interactivity, Game Creation, Design, Learning, and Innovation (pp. 376-385). Springer, Cham. https://doi.org/10.1007/978-3-31 9-76908-0. https://doi.org/10.1007/978-3-319-76908-0_36

[36] Parlakkilic, A. (2013). E-learning change management: Challenges and opportunities. Turkish Online Journal of Distance Education, 14(4), 54-68. https://doi.org/10.17718/tojde. 35820

[37] Petropoulou, O., Kasimatis, K., Dimopoulos, I., \& Retalis, S. (2014). LAe-R: A new learning analytics tool in Moodle for assessing students' performance. IEEE Technical Committee on Learning Technology, 16(1), 3. https://doi.org/10.1010101

[38] Preidys, S., \& Sakalauskas, L. (2010). Analysis of students' study activities in virtual learning environments using data mining methods. Technological and Economic Development of Economy, 16(1), 94-108. https://doi.org/10.3846/tede.2010.06

[39] Raadt, M. De, Watson, R., \& Toleman, M. (2004). Introductory Programming: What's H appening T oday and Will There B e A ny S tudents to T each T omorrow? In: ACE'04 Proceedings of the Sixth Conference on Australasian Computing Education. Australian Computer Society, Inc., 1-6.

[40] Rakic, S., Softic, S., Tasic, N., Turcin, I., Lüftenegger, E., \& Marjanovic, U. (2020). Student Performance on an E-Learning Platform: Mixed Method Approach. International Journal of Emerging Technologies in Learning, 15(2), 187-203. Slavko. https://doi.org/10. 3991/ijet.v15i02.11646

[41] Ramesh, V., Parkavi, P., \& Ramar, K. (2013). Predicting Student Performance: A Statistical and Data Mining Approach. International Journal of Computer Applications, 63(8), 3539. https://doi.org/10.5120/10489-5242

[42] Reyes, J. A. (2015). The skinny on big data in education: Learning analytics simplified. TechTrends, 59(2), 75-80. https://doi.org/10.1007/s11528-015-0842-1

[43] Rodgers, T. (2016). Student Engagement in the E-Learning Process and the Impact on Their Grades. August.

[44] Romero, C., \& Ventura, S. (2007). Educational data mining: A survey from 1995 to 2005. 33, 135-146. https://doi.org/10.1016/j.eswa.2006.04.005

[45] Saito, T. (2010). The Human Development Process and Informatics Education in the 21st Century. 354-360. https://doi.org/10.1007/978-3-642-15378-5_34

[46] Shaun, R., Baker, J. De, \& Inventado, P. S. (2014). Chapter 4: Educational Data Mining and Learning Analytics. Springer, Chapter 4, 61-75. https://doi.org/doi-org.ezproxy.lib.uts. edu.au/10.1007/978-1-4614-3305-7_4. https://doi.org/10.1007/978-1-4614-3305-7_4

[47] Skalka, J., Drlik, M., \& Obonya, J. (2019). Automated assessment in learning and teaching programming languages using virtual learning environment. IEEE Global Engineering Education Conference, EDUCON, April-2019. https://doi.org/10.1109/EDUCON.2019.87251 $\underline{27}$

[48] Smith, V. C., Lange, A., \& Huston, D. R. (2012). Predictive modeling to forecast student outcomes and drive effective interventions in online community college courses. Journal of Asynchronous Learning Network, 16(3), 51-61. https://doi.org/10.24059/olj.v16i3.275

[49] Tullis, T., Albert, B., \& Investments, F. (2008). Tips and Tricks for Measuring the User Experience Usability and User Experience 2008 UPA-Boston's Seventh Annual Mini UPA Conference. https://doi.org/10.1016/b978-0-12-373558-4.00003-0

[50] Watkins, K. E., \& Marsick, V. J. (1993). Sculpting the learning organization: Lessons in Art and Science of Systemic Change. Eric Ed365852, 6(4), 298. http://eric.ed.gov/?id=ED 365852 
[51] Yassine, S., Kadry, S., \& Sicilia, M. A. (2016). A framework for learning analytics in moodle for assessing course outcomes. IEEE Global Engineering Education Conference, EDUCON, 10-13-Apri (April), 261-266. https://doi.org/10.1109/educon.2016.7474563

[52] Zaharias, P., \& Poylymenakou, A. (2009). Developing a usability evaluation method for elearning applications: Beyond functional usability. International Journal of HumanComputer Interaction, 25(1), 75-98. https://doi.org/10.1080/10447310802546716

\section{Authors}

Juraj Obonya is doctoral student of the Department of Informatics, Constantine the Philosopher University in Nitra, Tr. Andreja Hlinku 1, 94901 Nitra, Slovakia.

Miroslav Kadlečík is doctoral student of the Department of Informatics, Constantine the Philosopher University in Nitra, Tr. Andreja Hlinku 1, 94901 Nitra, Slovakia. mkadlecik@ukf.sk

Article submitted 2020-02-11. Resubmitted 2020-05-22. Final acceptance 2020-05-22. Final version published as submitted by the authors. 